\title{
THE TABETIC PUPIL
}

To the Editors of The BRitish Journal of OpHTHALMOLOGY.

DEAR SIRS,-A few days ago I re-read a paper written by me and printed in the March (1941) number of your journal-the paper is entitled the Tabetic Pupil.

I was disappointed to discover that it contains a gross neurological error. Although this mistake does not affect the discussion, or the conclusions arrived at, yet in my opinion it does detract from the merit of the paper as a whole.

I would therefore he obliged if you would publish this letter of explanation. When dealing with the proprioceptive.impulses from the ocular muscles during accommodation I placed them as travelling in the motor ocular nerve.

This of course is incorrect - they pass in the ophthalmic division of $\mathrm{V}$ and reach the motor oculi nucleus via its mesencephalıc root. I do not know whether this function has been attributed to this root or not-but to suggest such a function to some extent clears the mist of obscurity which surrounds the somew hat nebulous description of its function given by some text books.

Yours faithfully,

Percival W. Leathart.

2, Howbeck Road, Birkenhead.

November 7, 1941

\section{THE DEMANDS OF THE SERVICES}

To the Editors of The British Journal of Ophthalmology.

DEAR SIRS,-The demand for ophthalmic "specialists" in the services is one of considerable urgency and is certain to increase. It is greatest in the army not only because of the latter's impressive size, but also because, even since the recent revision in standards of vision, it has undergone and is still in process of undergoing a revolutionary development towards mechanisation. The old army standard was based on the minimum visual requirements of the infantryman and, although there are now seven standards of visual acuity, some at least of these still represent little or no advance on the old standard. Every soldier should be able to spot an aeroplane at the earliest possible moment, yet Standard V, in which the corrected vision of each eye is only $6 / 24$, if in fact it does refer to 